\title{
Developing an HIV/AIDS risk communication intervention model among Myanmar migrant workers in a factory in Samut Sakhon, Thailand
}

\author{
Smith Boonchutima, Suchitra Sukonthasab, Parichart Satapitanonta \\ Chulalongkorn University, Thailand
}

\begin{abstract}
Introduction: In response to the heightened human immunodeficiency virus (HIV)/acquired immune deficiency syndrome (AIDS) epidemic in Samut Sakhon, Thailand, this study aimed to propose a communication model to raise awareness among migrant workers and examined its effect on the participants' knowledge, self-efficacy to take preventative measures, perceived susceptibility to HIV/AIDS, perceived severity of HIV/AIDS to their health, perceived benefits and barriers to taking preventive measures against HIV/AIDS, and self-reported behavioral changes.

Material and methods: A participatory risk communication campaign was designed based on the input from two focus groups consisting of 16 respondents in a factory and in-depth interviews with 10 local government and non-government officers responsible for HIV/AIDS prevention and control. With the cooperation of factory health volunteers recruited from the workers in the target factory, the intervention was developed and administered to 400 workers for two weeks starting on International Condom Day in 2017. The intervention components included events and activities, workshops and training, a media campaign, and quantitative and qualitative evaluations.

Results: The effects of the campaign on knowledge scores, stages of change in condom use and HIV testing, self-efficacy, and the perceived benefits and barriers to taking preventative measures against HIV/AIDS were found to be significant, but the effect of the media campaign on the perceived risk of contracting HIV was not significant (alpha 0.05).

Conclusions: The study found that the participation of the migrants contributed to the campaign's success in creating impacts on HIV/AIDS prevention and awareness among migrant workers in Samut Sakhon, Thailand. Significant increases in self-efficacy, knowledge, and condom use were reported by Myanmar workers following the media campaign.
\end{abstract}

HIV AIDS Rev 2019; 18, 4: 285-295 DOI: https://doi.org/10.5114/hivar.2019.88535

Key words: prevention, self-efficacy, condom, questionnaire, media campaign, changing attitude, vulnerability.

Address for correspondence: Suchitra Sukonthasab, Chulalongkorn University, Thailand,

e-mail: sukonthasab@hotmail.com
Article history:

Received: 14.04.2017

Received in revised form: 09.04.2018

Accepted: 07.05.2018

Available online: 10.03.2019
International Journal of HIV-Related Problem

HIV \& AIDS

R e v i e w 


\section{Introduction}

Acquired immune deficiency syndrome (AIDS) and human immunodeficiency virus (HIV) infection are major public health concerns around the globe. HIV/AIDS is one of the plagues threatening the existence of human beings in the $21^{\text {st }}$ century. Since the clinical diagnosis of AIDS in 1981, it is estimated that approximately 25 million people have died from the virus [1]. More than 100 million people have contracted HIV/AIDS, with 35 million presently living with the disease $[2,3]$.

The Asian-Pacific region is ranked second after subSaharan Africa as the region harboring the largest group of people infected with HIV. Thailand alone accounts for around 9\%, making it one of the countries with the highest number of HIV/AIDS infected populations [4]. In 2016 was estimated that out of over 60 million people living in Thailand, around 450,000 were infected with HIV and 6,400 had died due to AIDS connected diseases [5]. Even though the HIV transmission rate in Thailand has been declining, there are specific groups which have recorded significantly higher HIV infection rates compared to the entire population. Among these, migrant workers have been found to be the most vulnerable group to HIV/AIDS compared to the others (female and male sex workers, men-who-havesex-with-men [MSM], transgender individuals, and those who inject drugs) [6].

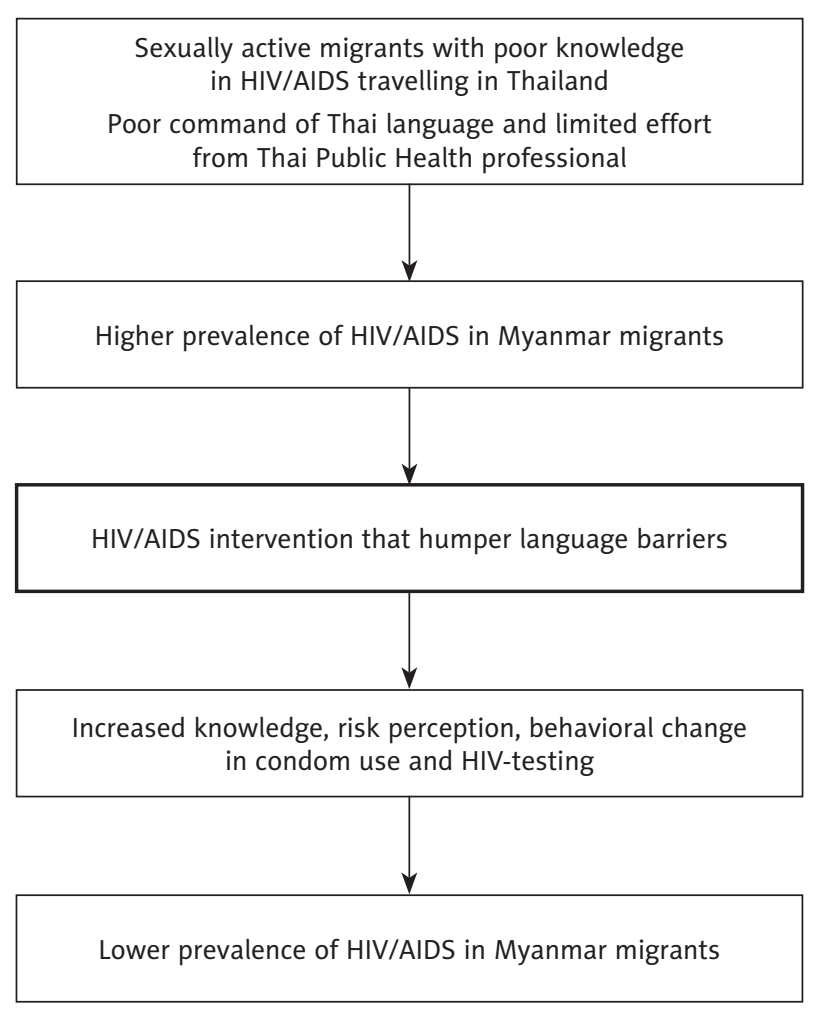

Figure 1. HIV infection process of Myanmar migrants in Thailand and possible intervention to reach the outcome
Migration is considered as one of the risk factors in the spread of HIV/AIDS due to issues such as lack of social protection, social exclusion, and failure to access quality healthcare services. Studies indicate that immigrants to Thailand drawn from neighboring nations such as Myanmar, Laos and Cambodia are four times more likely to get infected with HIV compared to the general population [4]. According to a United Nations Development Programme (UNDP) study conducted in 2012, the fishing industry was established as having the highest HIV prevalence rate among Thailand's migrants. It was found to have a $2.3 \%$ prevalence rate among fishery workers and $2 \%$ among fishermen [7]. This prevalence rate was considerably higher compared to that of farm workers and factory workers, which was $0.74 \%$ and $1.1 \%$, respectively. In a study completed in 2016 to determine the HIV prevalence rate among Myanmar migrants, it was revealed that out of a sample of over 2000 migrant workers in Thailand, over a half were uncertain of where to go for HIV testing [8] (Figure 1).

Samut Sakhon province in Thailand is one of the regions with the highest numbers of Myanmar migrants in the nation. There are approximately 200,000 migrants from Myanmar working in the seafood industry. According to the Care International Organization, a non-governmental organization in Thailand handling the health requirements of Myanmar migrants, there were 1929 cases of HIV infection between 1998 and 2000. Until the creation of migrant health insurance in 2016, many migrants had no access to health care services $[9,10]$.

According to Thailand's Ministry of Labor, $51 \%$ of undocumented migrant workers working and living in Thailand came from Cambodia, 42\% from Laos and 85\% from Myanmar [11]. Vulnerability and health risks associated with HIV/AIDS became prevalent in Thailand once these migrants arrived in the nation. They have no family support and lack any knowledge of the treatment for and prevention of HIV/AIDS. These migrants are faced with challenging situations, such as family pressure and lack of social support and are thus unable to exhibit consistent healthy behaviors $[11,12]$.

In general, those Myanmar migrants who do not work in firms related to exports live and work in an environment likely to increase their vulnerability to HIV/AIDS [10]. Most of the workers usually have a limited amount of free time. Their movements outside the factory compound are restricted due to language barriers and travelling costs. They maintain conservative values, such as ethnicity, nationality and religion. The environment generates limited opportunities for these workers to learn about HIV/AIDS. Those of undocumented status are restricted in their movements due to the fear of getting arrested by the police [11-14].

A majority of previous studies on migrant workers in Thailand have identified various factors related to HIV/ AIDS knowledge and risk behaviors. Some of the predominant factors include less knowledge regarding HIV/AIDS among agricultural workers and most particularly seafarers who recently migrated to Thailand [15-18]. The undocu- 
Table 1. Work hard for the family, abstain from HIV risk activities (step and activities)

\begin{tabular}{|c|c|}
\hline Step & Activities \\
\hline \multicolumn{2}{|l|}{ Step 1: Planning } \\
\hline $\begin{array}{l}\text { Pre-intervention } \\
\text { Overview of the project } \\
\text { and obtaining feedback } \\
\text { from factory health volunteers } \\
\text { ( } 3 \text { Sundays) }\end{array}$ & $\begin{array}{l}\text { Sunday one } \\
\text { 1. Overview of the project } \\
\text { 2. Ask the volunteers recruited by human resource personnel to introduce themselves } \\
\text { 3. Ask the volunteers to provide comments on the communication materials developed } \\
\text { by the study team in terms of content and style } \\
\text { 4. Project feasibility } \\
\text { 5. HIV/AIDS } 101 \\
\text { Sunday two } \\
\text { 6. HIV/AIDS lecture: mode of transmission, symptoms, treatment, right to treatment, } \\
\text { and prevention } \\
\text { 7. Active listening and counseling } \\
\text { Sunday three } \\
\text { 8. Allocating responsibility } \\
\text { 9. Practice the condom demonstration, quiz-moderating, photo-taking and posting on } \\
\text { social media } \\
\text { 10. Preparing the incentive } \\
\text { 11. Qualifying examination }\end{array}$ \\
\hline \multicolumn{2}{|l|}{ Step 2: Pre-testing } \\
\hline $\begin{array}{l}\text { Week } 1 \\
\text { One day before the intervention, } \\
\text { collecting the data on knowledge, } \\
\text { risk perception, condom use, and } \\
\text { HIV testing }\end{array}$ & $\begin{array}{l}\text { 12. Preparing the exam papers and training the proctors } \\
\text { 13. Human resource personnel recruit factory workers to take the exam } \\
\text { 14. Factory health volunteers and PhD students organizing and proctoring pre-tests } \\
\text { for } 200 \text { factory workers } \\
\text { 15. The study team conducts in-depth interviews with } 10 \text { factory workers to collect } \\
\text { qualitative data }\end{array}$ \\
\hline \multicolumn{2}{|l|}{ Step 3 Implementation } \\
\hline $\begin{array}{l}\text { Weeks } 2-3 \\
\text { Communication program (14 days) }\end{array}$ & $\begin{array}{l}\text { 16. Events and activities } \\
\text { - The launch, including opening speech by the factory owner and human resource } \\
\text { personnel. Group and individual photo-taking and posting photos on social media. } \\
\text { Activities: Condom demonstration and quizzes } \\
\text { - The closing ceremony, including tokens of appreciation and awards. } \\
\text { Activities: Condom demonstration and quizzes } \\
\text { - Both events were monitored by an invited non-governmental organization's health } \\
\text { volunteers to ensure accurate information } \\
\text { 17. Media campaign } \\
\text { - Radio announcement in the factory } \\
\text { - Posters } \\
\text { - Facebook posts }\end{array}$ \\
\hline \multicolumn{2}{|l|}{ Step 4: Post-testing } \\
\hline $\begin{array}{l}\text { Week } 4 \\
\text { One day after the intervention, } \\
\text { collecting the data on knowledge, } \\
\text { risk perception, condom use, and } \\
\text { HIV testing }\end{array}$ & $\begin{array}{l}\text { 18. Preparing the exam papers and training the proctors } \\
\text { 19. Human resource personnel recruit factory workers to take the exam } \\
\text { 20. Factory health volunteers and PhD students organizing and proctoring pre-tests } \\
\text { for } 200 \text { factory workers } \\
\text { 21. The study team conducts in-depth interviews with } 10 \text { factory workers to collect } \\
\text { qualitative data }\end{array}$ \\
\hline $\begin{array}{l}\text { Week } 6 \\
\text { Delayed post-test }\end{array}$ & $\begin{array}{l}\text { 22. Stop all communication activities for } 2 \text { weeks after the closing event } \\
\text { 23. Preparing the exam papers and training the proctors } \\
\text { 24. Human resource personnel recruit factory workers to take the exam } \\
\text { 25. Factory health volunteers and PhD students organizing and proctoring the pre-test } \\
\text { for } 200 \text { factory workers } \\
\text { 26. The study team conducts in-depth interviews with } 10 \text { factory workers to collect } \\
\text { ualitative data }\end{array}$ \\
\hline
\end{tabular}


mented status of Myanmar migrants coupled with their poor understanding of the Thai language and poor education level make them vulnerable to HIV/AIDS [19, 20]. Several studies have created various models for categorizing structural HIV/AIDS prevention interventions. Nonetheless, they have all featured a myriad of illustrative categories which are not comprehensive [21, 22]. As we are immersed in the various empirical findings relating to HIV/AIDS, we have identified the need to develop a customized communication intervention model that effectively prevents the spread of HIV/AIDS among Myanmar migrant workers.

The rationale of this study is to provide health professionals with a practical model which can be leveraged in understanding how a communication campaign can prevent the spread of HIV/AIDS among Myanmar migrant workers in Samut Sakhon province, Thailand. The study sought to explore how knowledge scores, stages of change in condom use and HIV testing, self-efficacy, and the perceived barriers and benefits of taking preventative measures against HIV/ AIDS are affected by the participatory campaign.

\section{Material and methods}

The study was qualitative and quantitative in nature. It used a cohort study and self-administered questionnaire to collect data regarding the effect of the campaign on HIV/ AIDS prevention among migrant workers in Samut Sakhon province in Thailand. The study used formative research to collect data from factory health volunteers (FHVs) to develop HIV/AIDS risk communication suitable for Myanmar migrant workers in a similar setting. The FHV intervention program is outlined in Table 1. This study differs from previous studies conducted on the topic in that it incorporates interviews and cohort studies to determine the effect of a communication campaign on HIV/AIDS prevention and awareness.

\section{Formative research and model design}

The FHV group was guided from the start of this research by a group of stakeholders drawn from the communities. The formative research phase was designed to evaluate how Myanmar migrant factory workers conceptualize the risk of HIV/AIDS in order to design the intervention's methods and contents. Ten in-depth interviews were conducted with male and female respondents representing efforts by non-governmental and governmental organizations addressing the HIV/AIDS menace in Samut Sakhon province. Two focus groups comprising 16 respondents, male and female, were utilized to collect data using the interview. Data collected from the interview revealed that the two groups received only limited knowledge about HIV/AIDS from public health organizations in Thailand. The respondents confirmed that the negative impact was due the lack of information on the risks of HIV/AIDS and on the treatment and prevention of HIV/AIDS.
The two focus groups also provided critical insights on the level of influence and support provided by the factory's human resource manager and the factory owner in communicating information concerning HIV/AIDS risks. They gave Myanmar migrant workers essential information relating to the prevention of HIV/AIDS, such as condom use and regular HIV testing. In addition, they also offered supportive feedback and comments to organize workshops for workers to increase their understanding of the treatment and prevention of HIV/AIDS. The factory owner and human resource personnel hoped to attain a low prevalence of HIV/AIDS among factory workers. They exemplified their commitment to support workers in overcoming the risk of HIV/AIDS in various ways. For instance, they suggested that the factory offices or canteens would be an excellent venue for the workshops intended to communicate the risk of HIV/AIDS. They informed the researchers that the major drawback in implementing their interventions was the absence of some workers due to their attitude and commitment. Manual workers were unable to attend the workshops due to work shifts and a negative attitude towards the intervention programs. For instance, some of them stated that they were not open to participating in any time-consuming activities.

Despite the unwavering support from the factory owner and officials in fighting the HIV/AIDS menace, interventions that would result in a disruption of the factory's activities would not be approved. They suggested that intervention strategies such as intensive workshops be staged during lunch hours or holidays. Involving policemen or political leaders in the intervention strategies was viewed as a negative impact on the campaign. Nonetheless, engaging public health professionals from non-governmental organizations and hospitals was considered beneficial to enhancing the success of the intervention campaign.

The researchers examined the formative research results and offered recommendations that culminated in the development of several guiding principles often referred to as interventions. These recommendations included a media campaign, empowerment, time efficiency, and notions of community participation in the intervention strategies.

\section{Factory health volunteer intervention components}

The factory health volunteer intervention comprises three primary components: activities and events, a media campaign, and a training/workshop curriculum. In each of the interventions, activities were intended to decrease the HIV/AIDS infection rate.

\section{Activities and events}

The activities and events of the factory health volunteers were drawn from the results of the in-depth interviews conducted, the two focus groups comprising 16 participants, 
and the agreement of the factory's owner and the human resource personnel.

Intervention activities occurred during lunch breaks and holidays. The rationale used in conducting these activities was to utilize workers' time spent chatting on mobile phones or relaxing. The researchers envisaged that Myanmar migrants should spend some of their free time lowering their exposure to HIV/AIDS. These activities received unwavering support from the factory personnel and sought to engage workers in communicating information about HIV/AIDS. These activities were promoted through a people empowerment model to eliminate misconceptions about HIV/AIDS. The primary objectives were to: 1) deliver accurate HIV/ AIDS information and support materials, 2) enhance contact between factory health volunteers and Myanmar factory workers, and 3) increase the perceived benefits of health-related activities and events.

Through raising awareness of the benefits of these events and activities, the volunteers would enhance Myanmar migrants' social support and access to condoms, thereby lowering the prevalence of HIV/AIDS among the workers. The researchers recognized that these events and activities could be stigmatized; hence, organized groups of FHVs were designed to act as hosts and invite their co-workers into these activities while making sure it was fun and a worthwhile experience. FHVs held two game-based events at the recreation area near the canteen, enabling workers to engage in the events for a change of routine. The first event was organized as a launching event and was staged on Monday (13/02/2017), the day before Valentine's Day, which was also International Condom Day. The second event was the closing occasion held on Friday (24/02/2017), the last working day of the second week.

In addition to promoting the events and activities, factory health volunteers were expected to be prepared to distribute materials and share content for the training events. These included condom packets, prevention information, demonstrations about correct condom use, quizzes, prizes, exhibitions, and refreshments. The theme "Work Hard for the Family, Avoid HIV" was communicated throughout the event to enhance awareness about the risks and perceived benefits of taking preventive measures against HIV/AIDS and to share accurate knowledge with the factory workers.

The researchers had a photo backdrop and frames made and invited Myanmar migrant factory workers to take photos and post them on the event's Facebook page in exchange for a daily necessity, such as water containers, shampoo, and soap, each valued at approximately $\$ 2$. The photos posted on the event's Facebook page were amplified to be viewed by more people in addition to those on the workers' friends lists. Immediately after the event, there were 70 likes on the Facebook page, and 401 likes at the end of the two-week intervention. Only $\$ 20$ was spent on boosting the posts; individuals who liked the posts were invited to like the event's Facebook page. No advertising was conducted to popularize the Facebook page. One tech-savvy FHV and one Myanmar research assistant were appointed as editors, their main duty being to interact with those who commented.

\section{Workshop and training components}

FHV training, workshops, and presentations of the HIV/ AIDS risk communication curriculum were conducted in the training room in the factory's human resource office. From December 2016 to January 2017, members of the study team presented the FHV curriculum to groups of up to 25 participants; training brochures were offered to all groups, and questions were answered. Each of the three presentations lasted approximately 3 hours and was conducted over three Sundays. On the first Sunday, there was an introduction to the project, which provided a mutual understanding of the goals and the possibility of organizing the intervention, and a presentation about information on HIV by a qualified Myanmar doctor. The second workshop was a lecture followed by a workshop on HIV/AIDS and its mode of transmission, symptoms, treatment, rights to treatment, and prevention. The last workshop was held to finalize the responsibilities of each factory health volunteer; to practice the condom demonstration, quiz moderating, photo taking and posting on social media; and to prepare the incentives and the qualifying examination.

Throughout all these activities, the study team repeatedly mentioned that only those from Myanmar could organize the proposed event that effectively. This was intended to raise the sense of belonging and the full participation of the Myanmar migrants. Moreover, the study team insisted on supporting their initiatives with the necessary knowledge of HIV/AIDS and communication skills. In the very last week before the intervention, the study team found that there were eight committed people who attended the curriculum multiple times and showed enthusiasm in organizing and inviting their friends to the events. They also requested T-shirts with the campaign logo to be made for the team of factory health volunteers and study teams. They wanted them to wear them every time they organized the activities during this intervention.

\section{Media campaign}

The media campaign included booklets, posters, video animation, a Facebook page, and a radio announcement. The researchers formed to focus groups to determine their perception of the campaign materials. The first was conducted using factory health volunteers to characterize how various combinations of images and text communicated a range of potential messages. The second was conducted with a group of experienced Myanmar health volunteers from HIV/AIDS non-government organizations to determine whether the content and images appropriately communicated the risk of HIV/AIDS.

The image selected was intended to be racially neutral, to make it possible to apply for another project targeting other ethnic groups in Thailand. The background of the posters and Facebook photos was very colorful, captured the viewers' attention, and stood out among the messages on the factory bulletin boards and the factory workers' Facebook timeline. The media campaign contained five key messages 
covering the following: mode of transmission, symptoms, prevention, treatment, and rights to treatment. The localized message strategy used for the booklets showed the façade of the factory, the list of the factory health volunteers' names, photos of the local hospital along with its address, map, contact details, and direction, and, more importantly, the phone number of the head of the factory health volunteers, who was also a Myanmar's human resource officer. Six radio announcements were read on the factory's loudspeakers by an elected factory health volunteer twice a day, during lunch and dinner breaks. After the unveiling, factory health volunteers intercepted factory workers to assess the need for clarification of the media campaign's message. Interestingly, some thought that the campaign was telling them to use condoms, while others understood the campaign as saying they should not trust their sexual partner to have unprotected sex with them. Some of the factory workers wanted to know if the factory health volunteers had HIV.

\section{The FHV intervention evaluation}

\section{Reflection and lessons learned}

The factory health volunteers who collaboratively developed and delivered the FHV intervention provided feedback on their experiences of implementing the FHV invention with the Myanmar factory-worker community.

Many factory health volunteers admitted they felt empowered, that they could do more with their acquired knowledge than merely passively keep it to themselves. Nonetheless, this intervention necessitated their active participation; hence they were encouraged to pass on the knowledge to other workers in the factory or members of their community in their own language in order to enhance their understanding about the risk, prevention, and treatment of HIV/AIDS. The FHVs observed that they felt appreciated, as they had been given the opportunity to do something beneficial for their community.

They also mentioned that the supervision by experienced Myanmar health volunteers from the non-government organization in the local area was essential and that this made them feel more confident to speak on HIV/AIDS or on health-related issues. Any misused words were corrected on the spot to prevent the spread of misinformation. Moreover, the experienced volunteers showed them additional techniques for advanced demonstrations, thus improving their skills and their understanding of the subject matter. On the other hand, the experienced Myanmar health volunteers reflected that they found the formation of the factory health volunteer group challenging but valuable. In addition, they also reported that the factory health volunteers organized the events more smoothly and were able to share their knowledge and demonstrate more accurately during the closing event than they had at the launch. The factory health volunteers mentioned that getting the factory workers to join the game booths within a limited time frame was one of the main challenges they faced in this study. They noted the potential power play of the game booths, in that these helped factory workers view the health volunteers as influential and trusted opinion leaders in the community. During the launch of the intervention activities and events, the factory owner presided over the ceremony and gave a speech which made many factory workers see the event as part of the factory's initiatives. They felt valued and trusted by the management and eager to participate in the planned event.

\section{In-depth interviews}

Ten in-depth interviews with male and female workers before and after the FHV event revealed a positive change in the assessment of HIV/AIDS risk, especially risky behavior, barriers to condom use and HIV testing, and the participation and satisfaction with the events. The workers reported that they had joined the launch of the events, but not their closing, as the activities there were the same as those at the launch. They also said that over the past two weeks they had obtained more knowledge of HIV/AIDS from listening to the radio announcements, looking at the posters, and following the campaign's Facebook page.

\section{Cohort study}

For the quantitative measurement of the efficacy of the media campaign, an HIV/AIDS questionnaire designed for use in this cohort study was administered to a sample consisting of 200 workers out of a total 400 workers (CL $=95 \%$, $\mathrm{CI}=4.9)$. Inclusion criteria for the sample included age 20-30 years, a good command of the Myanmar language, and willingness to sign the consent form on the initial page of the questionnaire. The sample was pre- and post-tested with the questionnaire, which had eight sections: (1) respondents' profile, HIV/AIDS knowledge, (2) perceived opportunity to contract HIV/AIDS, (3) perceived severity of HIV/AIDS to their health, (4) self-efficacy to enact preventive measures, (5) perceived benefits of and (6) perceived barriers to HIV/ AIDS prevention, and stages of behavioral change in (7) condom use and (8) HIV testing.

The selected age range (20-30 years) was assumed to be sexually active and to account for most Myanmar migrant workers in Thailand, according to immigration office records. The pre-test was conducted a week before the launch event, while the post-test was conducted one day after the closing event. A delayed post-test was conducted two weeks after the first post-test. The factory health volunteers, along with Myanmar graduates from a medical school in Thailand, participated in organizing and proctoring the exam sessions. The standard operating procedures for the exam were written down in detail, explained verbally, and rehearsed several times to ensure that the factory health volunteers' performance lived up to research standards. The mean differences among the three tests were assessed using repeated measures analysis. Post hoc analysis consisting of paired $t$-tests with 
Bonferroni correction was performed, with comparisons made across conditions at each of the three tests.

\section{Results}

The respondents were distributed equally in terms of sex (male $n=100$; female $n=100$ ), and almost equally in two age ranges (20-25 years old, $n=99,49.5 \%$; $26-30$ years old, $n=101,50.5 \%)$. All respondents had some level of education or vocational training. About half of the respondents had graduated from middle school (49.5\%). On average, they had resided in Thailand for approximately 3.6 years $(\mathrm{M}=43.90$ months, $\mathrm{SD}=33.57)$ and worked for the participating factory for 3.1 years $(\mathrm{M}=37.45$ months, $\mathrm{SD}=31.09)$ However, the standard deviation of length of stay and work was extremely high.

As for sexual behavior, about one out of three respondents $(n=60,30.0 \%)$ had engaged in sexual intercourse during the past four weeks. Almost all of those who reported engaging in sexual intercourse had never married. Only 7 unmarried respondents (3.5\%) reported that they had sexual intercourse and in addition did not believe that their partner had sex only with them.

The factory health volunteers were reported as the main source of information about HIV/AIDS for half of the respondents $(50.0 \%)$, followed by game booths in the pretest day and posters (40.0\%), Facebook post (34.5\%), and booklets (33.5\%). On average, each respondent received 2.8 types of sources of information. During the media campaign, no one received information on AIDS from sources other than those used in the campaign. The study found that the media campaign was effective in increasing the visibility of HIV-related issues among Myanmar migrant factory workers.

Variance analysis revealed that the effect of the media campaign on the knowledge scores was significant,

Table 2. Respondents' demographics, sexual behavior, and exposure to the media in the campaign

\begin{tabular}{|c|c|c|c|c|}
\hline $\begin{array}{l}\text { Respondents' demographics, sexual behavior, } \\
\text { and exposure to the media in the campaign }\end{array}$ & $n$ & $\%$ & Mean & $\begin{array}{l}\text { Standard } \\
\text { deviation }\end{array}$ \\
\hline \multicolumn{5}{|l|}{ Sex } \\
\hline Male & 100 & 50.0 & & \\
\hline Female & 100 & 50.0 & & \\
\hline \multicolumn{5}{|l|}{ Age } \\
\hline $20-25$ & 99 & 49.5 & & \\
\hline $26-30$ & 101 & 50.5 & & \\
\hline \multicolumn{5}{|l|}{ Education } \\
\hline \multicolumn{5}{|l|}{ No education } \\
\hline Primary school & 55 & 27.5 & & \\
\hline Middle school & 99 & 49.5 & & \\
\hline High school & 46 & 23.0 & & \\
\hline \multicolumn{5}{|l|}{ University level and above } \\
\hline Length of stay in Thailand & & & 43.90 & 33.567 \\
\hline Length of stay in factory & & & 37.45 & 31.093 \\
\hline \multicolumn{5}{|c|}{ Communication media respondents exposed to in the campaign } \\
\hline Posters & 80 & 40.0 & & \\
\hline Facebook posts & 69 & 34.5 & & \\
\hline Facebook videos & 60 & 30.0 & & \\
\hline Radio announcements & 59 & 29.5 & & \\
\hline Booklets & 67 & 33.5 & & \\
\hline Health volunteers in the factory & 100 & 50.0 & & \\
\hline Game booths (pre-test) & 80 & 40.0 & & \\
\hline Game booths (post-test) & 55 & 27.5 & & \\
\hline Number of media exposed to & & & 2.85 & 1.915 \\
\hline \multicolumn{5}{|l|}{ Exposure to other media during the campaign } \\
\hline \multicolumn{5}{|l|}{ Yes } \\
\hline No & 200 & 100.0 & & \\
\hline
\end{tabular}


$\mathrm{F}=257.513, p \leq 0.0001$. Post-hoc analyses using the Bonferroni post-hoc criterion for significance indicated that the average scores were significantly higher in the posttest $(M=7.94, S D=1.68)$ than in the pre-test $(M=4.07$, $\mathrm{SD}=1.39$ ). The effect of the media campaign on the perceived risk of contracting the HIV virus was not significant at the alpha 0.05 . The effect of the media campaign on the perceived severity of HIV/AIDS was significant, $\mathrm{F}=8.652, p=0.0004$. Post-hoc analyses using the Bonferroni post-hoc criterion for significance indicated that the average scores were significantly lower in the post- test $(\mathrm{M}=1.65, \mathrm{SD}=0.52)$ than in the pre-test $(\mathrm{M}=1.78$, $\mathrm{SD}=0.42)($ Table 3$)$.

The effect of the media campaign on self-efficacy to enact preventive measures against HIV/AIDS was significant, $\mathrm{F}=26.536, p \leq 0.0001$. Post-hoc analyses using the Bonferroni post-hoc criterion for significance indicated that the average scores were significantly higher in the posttest $(\mathrm{M}=1.86, \mathrm{SD}=0.39)$ than in the pre-test $(\mathrm{M}=1.52$, $\mathrm{SD}=0.69)$, and the delayed post-test $(\mathrm{M}=1.74, \mathrm{SD}=0.48)$. The average scores stayed significantly higher in the delayed post-test than in the pre-test.

Table 3. Pre-test, post-test and delayed post-test on knowledge, perceived opportunity, severity, self-efficacy, benefits, barriers and stages of change in condom use and HIV testing

\begin{tabular}{|c|c|c|c|c|c|}
\hline Factor & Mean & Standard deviation & $\mathrm{F}$ & Sig & Post \\
\hline \multicolumn{6}{|l|}{ Knowledge } \\
\hline Pre-test & 4.07 & 1.389 & \multirow[t]{3}{*}{257.513} & \multirow[t]{3}{*}{$<0.001$} & \multirow[t]{3}{*}{ Pre-post } \\
\hline Post-test & 7.94 & 1.685 & & & \\
\hline Delayed post-test & 7.67 & 1.749 & & & \\
\hline \multicolumn{6}{|l|}{ Opportunity } \\
\hline Pre-test & 1.83 & .381 & \multirow[t]{3}{*}{1.208} & \multirow[t]{3}{*}{0.301} & \\
\hline Post-test & 1.82 & .438 & & & \\
\hline Delayed post-test & 1.87 & .337 & & & \\
\hline \multicolumn{6}{|l|}{ Severity } \\
\hline Pre-test & 1.78 & .419 & \multirow[t]{3}{*}{8.652} & \multirow[t]{3}{*}{0.004} & \multirow{3}{*}{$\begin{array}{l}\text { Pre-post, } \\
\text { pre-delayed post, } \\
\text { post-delayed post }\end{array}$} \\
\hline Post-test & 1.65 & .519 & & & \\
\hline Delayed post-test & 1.65 & .519 & & & \\
\hline \multicolumn{6}{|l|}{ Self-efficacy } \\
\hline Pre-test & 1.52 & .687 & \multirow[t]{3}{*}{26.536} & \multirow[t]{3}{*}{0.000} & \multirow{3}{*}{$\begin{array}{l}\text { Pre-post, } \\
\text { pre-delayed post, } \\
\text { post-delayed post }\end{array}$} \\
\hline Post-test & 1.86 & .389 & & & \\
\hline Delayed post-test & 1.74 & .483 & & & \\
\hline \multicolumn{6}{|l|}{ Benefits } \\
\hline Pre-test & 3.09 & 1.142 & \multirow[t]{3}{*}{6.685} & \multirow[t]{3}{*}{0.002} & \multirow{3}{*}{$\begin{array}{c}\text { Pre-post, } \\
\text { pre-delayed post }\end{array}$} \\
\hline Post-test & 3.31 & .978 & & & \\
\hline Delayed post-test & 3.39 & .838 & & & \\
\hline \multicolumn{6}{|l|}{ Barriers } \\
\hline Pre-test & 1.99 & 1.236 & \multirow[t]{3}{*}{16.602} & \multirow[t]{3}{*}{$<0.001$} & \multirow{3}{*}{$\begin{array}{l}\text { Pre-post, } \\
\text { pre-delayed post }\end{array}$} \\
\hline Post-test & 2.56 & .889 & & & \\
\hline Delayed post-test & 2.51 & 1.017 & & & \\
\hline \multicolumn{6}{|l|}{ Condom Use } \\
\hline Pre-test & 2.45 & 1.606 & \multirow[t]{3}{*}{5.605} & \multirow[t]{3}{*}{0.004} & \multirow{3}{*}{$\begin{array}{c}\text { Pre-post, } \\
\text { pre-delayed post }\end{array}$} \\
\hline Post-test & 2.85 & 1.653 & & & \\
\hline Delayed post-test & 2.73 & 1.553 & & & \\
\hline \multicolumn{6}{|l|}{ HIV testing } \\
\hline Pre-test & 3.10 & 1.506 & \multirow[t]{3}{*}{9.846} & \multirow[t]{3}{*}{0.000} & Post-delayed post \\
\hline Post-test & 3.31 & 1.296 & & & \\
\hline Delayed post-test & 2.86 & 1.525 & & & \\
\hline
\end{tabular}


Variance analysis showed that the effect of the media campaign on the perceived benefits of enacting preventive measures against HIV/AIDS was significant, $F=6.685$, $p=0.0002$. Post-hoc analyses using the Bonferroni posthoc criterion for significance indicated that the average scores were significantly higher in the post-test $(M=3.31$, $\mathrm{SD}=0.98)$ than in the pre-test $(\mathrm{M}=3.09, \mathrm{SD}=1.14)$. The delayed post-test scores $(\mathrm{M}=3.39, \mathrm{SD}=0.84)$ were found to rise significantly higher than in the pre-test. The effect of the media campaign on the perceived barriers to enacting preventive measures against HIV/AIDS was significant, $\mathrm{F}=16.602, p \leq 0.0001$. Post-hoc analyses using the Bonferroni post-hoc criterion for significance indicated that the average scores were significantly higher in the posttest $(\mathrm{M}=2.56, \mathrm{SD}=0.89)$ than in the pre-test $(\mathrm{M}=1.99$, $\mathrm{SD}=1.24)$. The delayed post-test scores $(\mathrm{M}=2.51$, $\mathrm{SD}=1.02$ ) were found to slightly decrease from the posttest scores, yet were significantly higher than the pre-test. The effect of the media campaign on the stages of change in condom use was significant, $\mathrm{F}=5.605, p=0.0004$. Posthoc analyses using the Bonferroni post-hoc criterion for significance indicated that the average scores were significantly higher in the post-test $(\mathrm{M}=2.85, \mathrm{SD}=1.65)$ than in the pre-test $(\mathrm{M}=2.45, \mathrm{SD}=1.61)$. The delayed post-test scores $(\mathrm{M}=2.73, \mathrm{SD}=1.55)$ were found to slightly decrease from the post-test scores, yet were significantly higher than the pre-test scores. The variance scores showed that the effect of the media campaign on the stages of change in obtaining HIV testing was significant, $\mathrm{F}=9.846, p \leq 0.0001$. Post-hoc analyses using the Bonferroni post-hoc criterion for significance indicated that the average scores were significantly higher in the post-test $(\mathrm{M}=3.33, \mathrm{SD}=1.30)$ than in the delayed post-test $(\mathrm{M}=2.86, \mathrm{SD}=1.52)$.

\section{Discussion}

The involvement of Myanmar workers in promoting sexual health is the key to the success of this HIV/AIDS risk communication model, as it can overcome language barriers and serve as a sustainable approach for other health issues. This quantitative study showed that Myanmar migrants working in a Samut Sakhon factory encounter numerous challenges in accessing health care services due to their immigrant status and tight working schedule. This is aligned with the UNAIDS 2010 study, which revealed that migrant workers in Samut Sakhon work and live in an environment that aggravates their vulnerability to HIV/AIDS. During an interview between Myanmar migrants and factory health volunteers, it was acknowledged that these workers usually engage in unprotected sex and maintain multiple sexual relationships. The results from these activities were confirmed by the data collected in this study, which revealed that one out of the three sampled respondents, representing 30\%, engaged in sexual intercourse during the last four weeks of the study. According to Archavanitkul et al., Myanmar migrants living in Thailand have a higher risk of contracting HIV/AIDS because they practice risky sexual behavior.
Similar to the findings of Mondal et al., male Myanmar migrants who were unmarried engaged in regular sexual behavior [23].

The findings revealed that FHV were the main source of information for Myanmar migrant factory workers, followed by game booths, Facebook posts, and booklets. Out of the media used to convey information about the transmission, treatment, symptoms, prevention, and rights to treatment, each participant received on average 2.8 types of information. These findings are corroborated by Khin's study [24, 25], which found that Myanmar migrants in Thailand obtained information from healthcare workers. According to research, the language barrier and financial hardship were some of the major challenges affecting Myanmar migrants' access to information and knowledge of HIV/ AIDS [27, 28]. Although there is no empirical research linking poverty to HIV/AIDS, financial hardship may affect migrants' access to smart devices, such as computers, smartphones, and tablets, needed to access social media platforms such as Facebook. This study revealed that offline interventions such as volunteers and game booths should be considered in the model for communicating the risk of HIV/AIDS.

In this survey, the effect of the media campaign on the knowledge scores was found to be significant. The posthoc analyses conducted using the Bonferroni post-hoc criterion for significance indicated that the average scores were significantly higher in the post-test than in the pretest. This finding was consistent with Jung et al's study [29], which found that a media campaign was effective in increasing knowledge about the transmission, prevention, and treatment of HIV/AIDS. Variance analysis on the effect of the media campaign on migrant workers' perceived risk of becoming infected with the HIV virus did not show a significant effect, while the impact of the media campaign on the perceived severity of HIV/AIDS was found to be significant. Despite the deviation in the perceived risk score, the intervention strategies used in this study were largely effective in educating Myanmar migrants about the risk of HIV/AIDS, thus lowering the perceived severity of the disease. Empirical research has extensively documented that HIV/AIDS patients often experience stigmatization and discrimination due to the perceived severity of their ailment, given the circulating misconception that the epidemic is life-threatening [27, 29].

Variance analysis on the effect of the media campaign on self-efficacy to perform preventive measures against HIV/AIDS found it to be significant, indicating that the proposed risk communication model was effective in raising awareness among Myanmar migrants on the importance of enacting preventive measures regarding HIV/AIDS. Further variance analysis on the effect of the media campaign on the perceived benefits to enacting preventive measures against HIV/AIDS found it to be significant, with the average scores being higher in the post-test compared to the pretest. These findings were consistent with a study by Keating, Meekers, and Adewuyi [30], which found that media campaign strategies were effective in raising awareness about 
the risk of HIV/AIDS, the perceived severity of the disease, and in enhancing the perceived importance (self-efficacy) of performing preventative strategies against HIV/AIDS. Keating et al's findings also corroborated the variance analysis on the effect of the media campaign on the perceived barriers to enacting preventive measures against HIV/AIDS, which was found to be significant, with the average scores significantly higher in the post-test than in the pre-test.

The primary objectives of the different types of intervention strategies used in this study were to deliver accurate information about HIV/AIDS materials and increase the perceived benefits of health-related activities and events. Variance analysis revealed that the media campaign employed in this research was effective in educating Myanmar migrant workers on the correct use of condoms. In addition, the campaign was successful in compelling migrants to perform regular HIV testing to overcome the risk of HIV/AIDS. According to Gupta and Singh, there is a strong correlation between a positive attitude towards HIV/AIDS and having accurate knowledge about the epidemic [31]. The findings of this study were mirrored in the variance analysis, where knowledge levels were observed to increase with the running of an effective media campaign. The types of media campaign tools employed in this study included booklets, posters, video animation, game booths, a Facebook page and radio announcements. Of these, Myanmar factory volunteers and game booths were the most effective media in communicating about the transmission, symptoms, prevention, treatment, and rights to treatment of HIV/AIDS. The study concludes that Myanmar workers should be used to promote the sexual health of migrants, thereby enhancing the success of the proposed risk communication model.

\section{Conclusions}

This study found high scores regarding the effect of a media campaign on the perceived barriers to enacting preventative measures against HIV/AIDS, lowering the perceived severity of the disease, and enhancing awareness of the perceived benefits of enacting preventive measures against HIV/ AIDS. Notably, significant increases in knowledge, self-efficacy, and condom use were observed. The results underlined the importance of involving Myanmar workers in promoting awareness of the sexual health of migrants. The Department of Disease Control should use Myanmar workers and game booths in order to communicate information about the risk of HIV/AIDS. Myanmar workers were found to be effective in communicating this information, since workers find it challenging to obtain access to healthcare facilities where there are plenty of materials and professionals to deliver information on the subject. The study recommends that Myanmar migrant workers be used by government and non-governmental organizations to communicate information concerning the transmission, symptoms, prevention, treatment, and rights to treatment of HIV/AIDS. Migrants should undergo relevant training to equip them with knowledge regarding HIV/AIDS to allow them to effectively serve as educative peers. Myanmar factory volunteers and game booths should be the primary media for conveying information about HIV/AIDS. The proposed risk communication model can be qualified as effective in delivering information about the transmission, treatment, prevention and right to treatment of HIV/AIDS, since high scores were reported in the majority of the variables, aside from the opportunity to contract the HIV virus. Notwithstanding, non-government and governmental organizations should explore possible offline interventions that can be used to enhance the effectiveness of the proposed risk communication model.

\section{Acknowledgements}

The authors extend their appreciation to Dr. Chit Dee Dee and Dr. Sai Pye for their unwavering support and guidance in completing this study. We are indebted to the volunteers, public health officials, Myanmar migrant factory workers, factory owner and human resource personnel for their support in the implementation of HIV/AIDS risk communication intervention strategies. A sincere thank you to John Kubuka for his constructive criticism and assistance in improving, editing, and proofreading this manuscript. This study was funded by the Faculty of Sports Science, Chulalongkorn University.

\section{Conflict of interest}

The authors declare no potential conflicts of interest with respect to the research, authorship, and/or publication of this article.

\section{References}

1. Merson MH. The HIV-AIDS pandemic at 25 - the global response. N Engl J Med 2006; 354: 2414-2417.

2. Idele P, Gillespie A, Porth T, Suzuki C, Mahy M, Kasedde S, et al. Epidemiology of HIV and AIDS among adolescents: current status, inequities, and data gaps. J Acquir Immune Defic Syndr 2014; 66: S144-S153.

3. Global report: UNAIDS report on the global AIDS epidemic 2013. UNAIDS, Geneva 2013.

4. Joint United Nations Programme on HIV/AIDS (UNAIDS). The gap report. UNAIDS, Geneva 2014.

5. UNAIDS. Data Book. Geneva, 2017.

6. NAC. Thailand national operational plan accelerating ending AIDS, 2015-2019. National AIDS Management Center, Ministry of Public Health, Nonthaburi 2014.

7. UNDP. Meeting report: consultation on the memorandum of understanding to reduce HIV vulnerability associated with population movement. Bangkok, 11-13 July 2012.

8. Musumari PM, Chamchan C. Correlates of HIV testing experience among migrant workers from Myanmar residing in Thailand: a secondary data analysis. PLoS One 2016; 11: e0154669.

9. CARE. HIV/AIDS and Mobile Populations (workshop report). CARE International, Bangkok 2000.

10. CARE. Primary Survey Reports on Study Attitudes and Behaviors Related to HIV/AIDS Prevention and Family Planning Among Migrants from Myanmar Working in Thailand. CARE International, Bangkok 2001.

11. UNAIDS. Migration and HIV/AIDS in Thailand. International Organization for Migration, Bangkok 2010. 
12. Thu M, Kyu HH, Van der Putten M. Knowledge, attitude and practices on HIV/AIDS prevention among Myanmar migrants in Maha Chai, Samut Sakhon Province, Thailand. Doctoral dissertation, Master's thesis, College of Public Health, Chulalongkorn University, 2003.

13. UNICEF. Situational analysis of young people at high risk of HIV exposure in Thailand. UNICEF, Bangkok 2008.

14. Zaw MM. Assessment of knowledge, attitudes and risk behaviors regarding HIV/AIDS among Myanmar migrant workers in Bangkok, Thailand. Doctoral dissertation. College of Public Health, Bangkok 2002.

15. Fuller TD, Chamratrithirong A. Knowledge of HIV risk factors among immigrants in Thailand. J Immigr Minor Health 2009; 11: 83-91.

16. Mullany LC, Maung C, Beyrer C. HIV/AIDS knowledge, attitudes, and practices among Burmese migrant factory workers in Tak Province, Thailand. AIDS Care 2003; 15: 63-70.

17. Ford K, Chamratrithirong A. Cross border migrants: duration of residence, mobility and susceptibility to HIV infection. International Journal of Migration, Health and Social Care 2012; 8: 127-133.

18. Oppenheimer E, Bunnag M, Stern A. HIV/AIDS and Cross-Border Migration: A Rapid Assessment of Migrant Population Along the ThaiBurma (Myanmar) Border Regions. Institute of Asian Studies Chulalongkorn University, 1998.

19. Tangmunkongvorakul A, Musumari PM, Srithanaviboonchai K, Manoyos V, Techasrivichien T, Suguimoto SP, et al. "When I first saw a condom, I was frightened": a qualitative study of sexual behavior, love and life of young cross-border migrants in urban Chiang Mai, Thailand. PLoS One 2017; 12: e0183255.

20. Pinyosinwat T. PHAMIT: A program on HIV/AIDS prevention among migrant workers. Field Actions Science Reports, 2009. Available at: http://Factsreports.revues.org/310.

21. Sweat MD, Denison JA. Reducing HIV incidence in developing countries with structural and environmental interventions. AIDS 1995; 9: S251-S257.

22. Blankenship KM, Bray SJ, Merson MH. Structural interventions in public health. AIDS 2000; 14: S11-S21.

23. Mondal MN, Hoque N, Chowdhury R, Moni SY, Howard J, Choudhury SR. Risky sexual behaviors and HIV vulnerability of male migrant workers in Rajshahi City, Bangladesh. Epidemiology 2014; 4 : 2161-1165.

24. Khin A. HIV/AIDS problem of migrants from Burma in Thailand. 2009. Available at: http://www.burmawatch. org/com-khin-hiv-aidsburmese-migrants-thailand.pdf.

25. Karkee R, Shrestha DB. HIV and conflict in Nepal: relation and strategy for response. Kathmandu Univ Med J (KUMJ) 2006; 4: 363-367.

26. Holt BY, Effler P, Brady W, Friday J, Belay E, Parker K, et al. Planning STI/HIV prevention among refugees and mobile populations: situation assessment of Sudanese refugees. Disasters 2003; 27: 1-15.

27. Ford K, Chamratrithirong A. Migrant seafarers and HIV risk in Thai communities. AIDS Educ Prev 2008; 20: 454-463.

28. Plewes K, Lee T, Kajeechewa L, Thwin MM, Lee SJ, Carrara VI, et al. Low seroprevalence of HIV and syphilis in pregnant women in refugee camps on the Thai-Burma border. Int J STD AIDS 2008; 19 833-837.

29. Jung M, Arya M, Viswanath K. Effect of media use on HIV/AIDSrelated knowledge and condom use in Sub-Saharan Africa: a crosssectional study. PLoS One 2013; 8: e68359.

30. Keating J, Meekers D, Adewuyi A. Assessing effects of a media campaign on HIV/AIDS awareness and prevention in Nigeria: results from the VISION Project. BMC Public Health 2006; 6: 123.

31. Gupta K, Singh SK. Social networking, knowledge of HIV/AIDS and risk-taking behavior among migrant workers. Journal of Population (Jakarta, Indonesia) 2003; 9: 51-80. 